Journal of Applied Pharmaceutical Science Vol. 6 (01), pp. 130-136, January, 2016

Available online at http://www.japsonline.com

DOI: 10.7324/JAPS.2016.600121

ISSN 2231-3354 (cc) EY-NC-SA

\title{
Free Radical Scavenger Activity of Cinnamyl Chitosan Schiff Base
}

\author{
T M Tamer ${ }^{1,2 *}$, Katarina Valachová ${ }^{2}$, Mohamed Samir Mohyeldin ${ }^{3}$, Ladislav Soltes ${ }^{2}$ \\ ${ }^{1}$ Polymer Research Department, Advanced Technologies and New Materials Research Institute (ATNMRI), City of Scientific Research and Technological \\ Applications (SRTA-City), New Borg El-Arab, 21934, Alexandria, Egypt. ${ }^{2}$ Laboratory of Bioorganic Chemistry of Drugs, Institute of Experimental \\ Pharmacology and Toxicology, SK-81404 Bratislava, Slovakia. ${ }^{3}$ Chemistry Department, Faculty of Science, University of Jeddah, Osfan, P. O. Box: 80203 , \\ Jeddah 21589, Saudi Arabia.
}

\begin{tabular}{|c|c|}
\hline ARTICLE INFO & ABSTRACT \\
\hline $\begin{array}{l}\text { Article history: } \\
\text { Received on: } 30 / 09 / 2015 \\
\text { Revised on: } 11 / 10 / 2015 \\
\text { Accepted on: } 09 / 11 / 2015 \\
\text { Available online: } 26 / 01 / 2016\end{array}$ & $\begin{array}{l}\text { In this study, new cinnamyl chitosan schiff base was evaluated as antioxidant material. Antioxidant activity was } \\
\text { measured by two different popular methods (uninhibited/inhibited hyaluronan degradation and decolorization of } \\
\text { ABTS methods). the results show decrease the hydrogen donation behavior of chitosan after coupling with } \\
\text { cinnamaldehyde, in the other hand, ABTS method show increase the electron donation activity of cinnamyl } \\
\text { chitosan than the chitosan itself. }\end{array}$ \\
\hline $\begin{array}{l}\text { Key words: } \\
\text { Chitosan, Cinnamyl chitosan, } \\
\text { Schiff base, Antioxidant, } \\
\text { Rotational viscometer, } \\
\text { ABTS, Hyaluronan. }\end{array}$ & \\
\hline
\end{tabular}

\section{INTRODUCTION}

Oxidation stress of free radicals attracted the attention of scientists over last years. Role of these free radicals as primary cause of several diseases driving them to condense their studies to identify their origin, mechanisms of their action and of course the best ways to scavenge them and decrease their harmful. Phenolic components have a good scavenger activity against free radicals and forming with it a more stable intermediated that limited its risk (Huang et al., 2011; Muchuweti et al., 2007, Shan et al., 2005). Chitosan is biocompatible, biodegradable, nontoxic renewable biopolymer produced by alkali treatment of chitin (the second most abundant natural polysaccharide next to cellulose). Chitin found in the composition of crustacean shells. Chitin

\footnotetext{
* Corresponding Author

Polymer Research Department, Advanced Technologies and New Materials Research Institute (ATNMRI), City of Scientific Research and Technological Applications (SRTA-City), New Borg El-Arab, 21934, Alexandria, Egypt Email: ttamer85@gmail.com
}

consists of $\quad \beta \quad(1 \rightarrow 4)$-2-acetamido-2-deoxy-d-glucopyranose (GlcNAc) as a repeating unit. Deacetylation of chitin yields chitosan, which is actually a copolymer of GlcNAc and B-(1 $\rightarrow 4)$ 2-amino-2-deoxy-d-glucopyranose with deacetylation greater than $60 \%$. Chitosan was found in several applications including cosmetics, artificial skin, photography, food and nutrition, ophthalmology and wastewater treatment, wound healing (Kumar et al., 2007; Shahidi et al., 1999; Dodane et al., 1998; Jeon et al., 2000; Mohy eldin et al., 2008; 2015a).

Presence of different functional groups along chitosan backbone (i.e.; hydroxyl and amine groups) simplifies its chemical modifications. Several derivatives of chitosan were prepared recently including methylation (Curti et al., 2003), carboxylation (Chen and Park., 2003), sulfonation (Vongchan et al., 2002), schiff base formation (Kenawy et al., 2015; Mohy Eldin et al., 2015b; Soliman et al., 2013).

This study was performed to evaluate antioxidant properties of cinnamyl chitosan schiff base and comparing its activity to citosan itself. 


\section{MATERIALS AND METHODS}

\section{Materials}

Shrimp shells was collect from wastes of seafood restaurants in Alexandria - Egypt, acetic acid (purity 99.8\%) and sodium hydroxide pellets (purity 99-100\%,) were obtained from Sigma Aldrich (Germany). Cinnamaldehyde (Purity 98\%) was obtained from Scharlau, (Spain). The high-molar-mass hyaluronan sample Lifecore P9710-2A, kindly donated by Lifecore Biomedical Inc., Chaska, MN, USA (Mr 808.7 kDa;

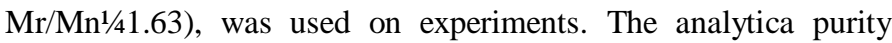
grade $\mathrm{NaCl}$ and $\mathrm{CuCl}_{2} \cdot 2 \mathrm{H}_{2} \mathrm{O}$ (Slavus Ltd., SK-Bratislava); Lascorbic acid and $\mathrm{K}_{2} \mathrm{~S}_{2} \mathrm{O}_{8}$ (p.a. purity, $\max 0.001 \%$ nitrogen; Merck, Germany); 2,2'-azinobis [3-ethylbenzothiazoline-6sulfonic acid] (ABTS; purum, >99\%; Fluka, Germany) were used.

\section{Methods}

\section{Extraction of chitin from shrimp Shells}

According to Islama, et al., (2011), the process mainly involved the following steps: Demineralizations of shells. In this step, the shells were dispersed in $5 \% \mathrm{HCl}$ at room temperature in the ratio of $1: 14(\mathrm{w} / \mathrm{v})$. After 24 hours, the shells were quite squashy and were rinsed with water to remove acid and calcium chloride., The de-mineralized shells were then treated with 5\% $\mathrm{NaOH}$ at room temperature for 24 hours in ratio of 12:1 (v/w). The residue was then collected and washed to neutrality in running tap water and then distilled water. The obtained product is chitin.

\section{Preparation of chitosan from chitin}

According to Rigby method (1936) preparation of chitosan is simply deacetylation of chitin in alkaline medium (figure 1). Removal of acetyl groups from the chitin was achieved by using $50 \% \mathrm{NaOH}$ solution with a solid to solution ratio of 1:50 (w/v) at $100-120{ }^{\circ} \mathrm{C}$ for 12 hours. The resulting chitosan was washed to neutrality with distilled water.

\section{Preparation of cinnamyl chitosan from chitosan}

Cinnamyl chitosan schiff base was prepared according to our previous work (Mohy Eldin et al., 2015b). Briefly, Previously purified chitosan $(1 \mathrm{~g})$ was dissolved in $50 \mathrm{ml}$ of $2 \%$ acetic acid and stirred at room temperature for $6 \mathrm{~h}$, the resulting viscous solution was filtered through cloth cheese to remove undissolved particles and $10 \mathrm{ml}$ of ethanol containing definite amount of cinnamaldehyde was added to solution under stirring to have viscous solution. This mixture was stirred for $6 \mathrm{~h}$ at $50{ }^{\circ} \mathrm{C}$. The formation of a deep yellow gel refers to formation of the chitosan schiff base (figure 2). The resulting product was added to excess of $5 \%$ sodium hydroxide solution. The precipitate was filtered and washed with water and ethanol several times to remove un-reacted cinnamaldehyde, the product was filtered and dried in a vacuum oven at $60{ }^{\circ} \mathrm{C}$ overnight.

\section{Antioxidant evaluation ABTS method}

For the ABTS decolorization assay, the radical cations were pre-formed by the reaction of an aq. soln. of $\mathrm{K}_{2} \mathrm{~S}_{2} \mathrm{O}_{8}(3.30$ $\mathrm{mg})$ in $\mathrm{H}_{2} \mathrm{O}(5 \mathrm{ml})$ with $\mathrm{ABTS}(17.2 \mathrm{mg})$. The resulting bluish green radical cation soln. was stored overnight in the dark below 0 ${ }^{\circ} \mathrm{C}$. Before experiment, the soln. $(1 \mathrm{ml})$ was diluted into a final volume $(60 \mathrm{ml})$ acetic acid solution $(0.5 \%)$. chitosan (or aminated chitosan) solution $(0.5 \%)$ stock solutions were prepared in acetic acid $(0.5 \%)$. A modified ABTS assay (Rapta et al., 2009) was used to test the radical-scavenging efficiency applying a UV-1800 spectrophotometer (SHIMADZU, Japan). The UV/VIS spectra were recorded in defined times, in 1-cm quartz UV cuvette after mixing of antioxidant solution $(50 \mu \mathrm{l})$ with an ABTS. soln. $(2 \mathrm{ml})$.
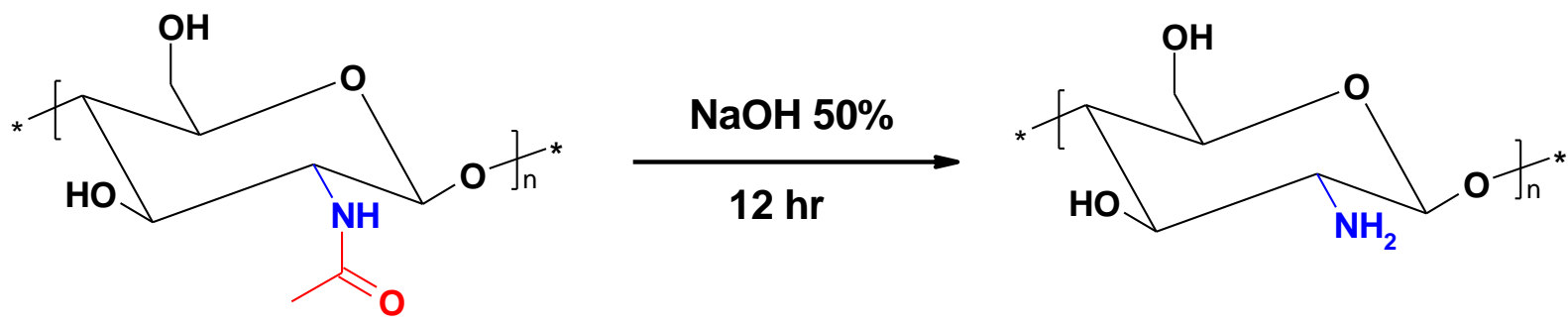

Fig. 1: Preparation of Chitosan.

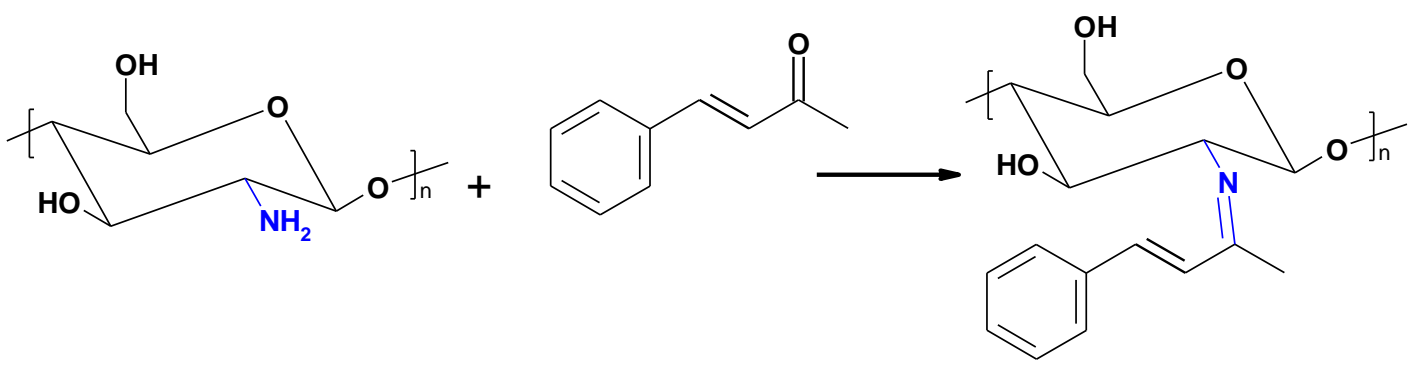

Fig. 2: Schematic preparation of Cinnamyl chitosan from chitosan. 


\section{Rotational viscometry method}

For the rotational viscometry measurements, a hyaluronan soln. $(2.5 \mathrm{mg} / \mathrm{ml})$ was prepared in the dark, standing at room temperature in an aqueous. $\mathrm{NaCl}$ soln. $(0.15 \mathrm{M})$ in two steps: first, the solvent $(4.0 \mathrm{ml})$ was added to a hyaluronan powder $(20$ $\mathrm{mg})$, and, within $6 \mathrm{~h}$, the same solvent $(3.85 \mathrm{ml})$ was added. The stock solutions $(16 \mu \mathrm{M})$ of ascorbic acid, polymer solution $(0.5 \%)$ stock solutions were prepared in acetic acid $(0.5 \%) . \mathrm{CuCl}_{2}(160$ $\mu \mathrm{M})$ were also prepared. Before starting to monitor the kinetics of the hyaluronan degradation via rotational viscometry, the mixture $(8.0 \mathrm{ml})$, consisting of the biopolymer soln. of the concentration as stated above, ascorbic acid $(100 \mu \mathrm{M}), \mathrm{Cu}$ II ions $(1.0 \mu \mathrm{M})$, and certain amount of chitosan (or aminated chitosan) solution were transferred into the Teflon cup reservoir of the Brookfield LVDVIIPRO digital rotational viscometer (Brookfield Engineering Labs., Inc., Middleboro, MA, USA). The experimental set was carried out by adding the chitosan (or aminated chitosan) solution at the beginning of degradation and also after $1 \mathrm{~h}$ of degradation start. The data acquisition of the viscometer output parameters was performed by recording within $2 \mathrm{~min}$ after the onset of the experiment. Time-dependent changes of the dynamic viscosity values of the system were measured at $25.0 \pm 0.1{ }^{\circ} \mathrm{C}$ within $3 \mathrm{~min}$ intervals for up to $5 \mathrm{~h}$. The viscometer teflon spindle rotation rate was $180 \mathrm{rpm}$, i.e., at the shear rate equaling $237.6 \mathrm{~s}^{-1}$ (Soltes et al., 2007; Soltes et al., 2005).

\section{RESULTS AND DISCUSSION}

\section{Antioxidant evaluation}

In this study, antioxidant activity of new chitosan derivate was done using our two established methods.
Hydroxyl and alkyl free radical scavenger activity was measured by rotational viscometry method beside measure the free radical scavenger activity via ABTS method.

\section{Rotational viscometry method}

In this method, uninhibited and inhibited hyaluronan degradation under free radical stress was used to evaluate chitosan antioxidant activity. This standardized method is, in general, used to mimic the pathophysiological situation, which may occur at the early stage of acute joint inflammation (Hrabarova et al., 2010) according to method, Hyaluronan was induced to degradation using Weissberger's oxidative system (ascorbate plus $\mathrm{Cu}$ II ions) that generate hydroxyl radical attract hyaluronan to start a chain radical degradation reaction let to split the hyaluronan chains. See reaction scheme (figure 3,4)

On application of Weissberger's system, the hyaluronan degradation was evidenced by the gradual decline of its dynamic viscosity. Figure (5) show the time dependant of hyaluronan degradation in neutral and inflammation conditions in absent and presence of chitosan and cinnamyl chitosan. by applying chitosan to inflammatory induce degradation (i.e. acidic condition) in the beginning of degradation (where $\mathrm{OH}$ radical is the dominant free radical species) chitosan show moderated scavenger of hydroxyl radicals results its functional groups (hydroxyl and amine groups) (Xue et al., 1998; Muzzarelli et al., 1997; Park et al., 2004; Sousa et al., 2009;Xie et al., 2001), this effect was depressed in cinnamyl derivatives that may be attributed to consumption of chitosan amine groups in new schiff base bond.

The same results were obtained when applying chitosan and cinnamyl chitosan after one hour of reaction onset where the alkyl and hyaluronan macroradicals were dominated. (Figure 6).

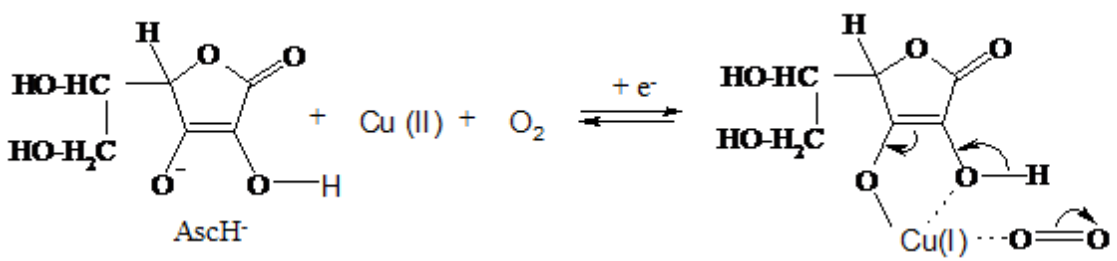<smiles></smiles>

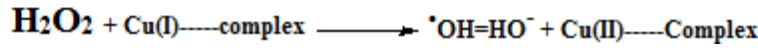



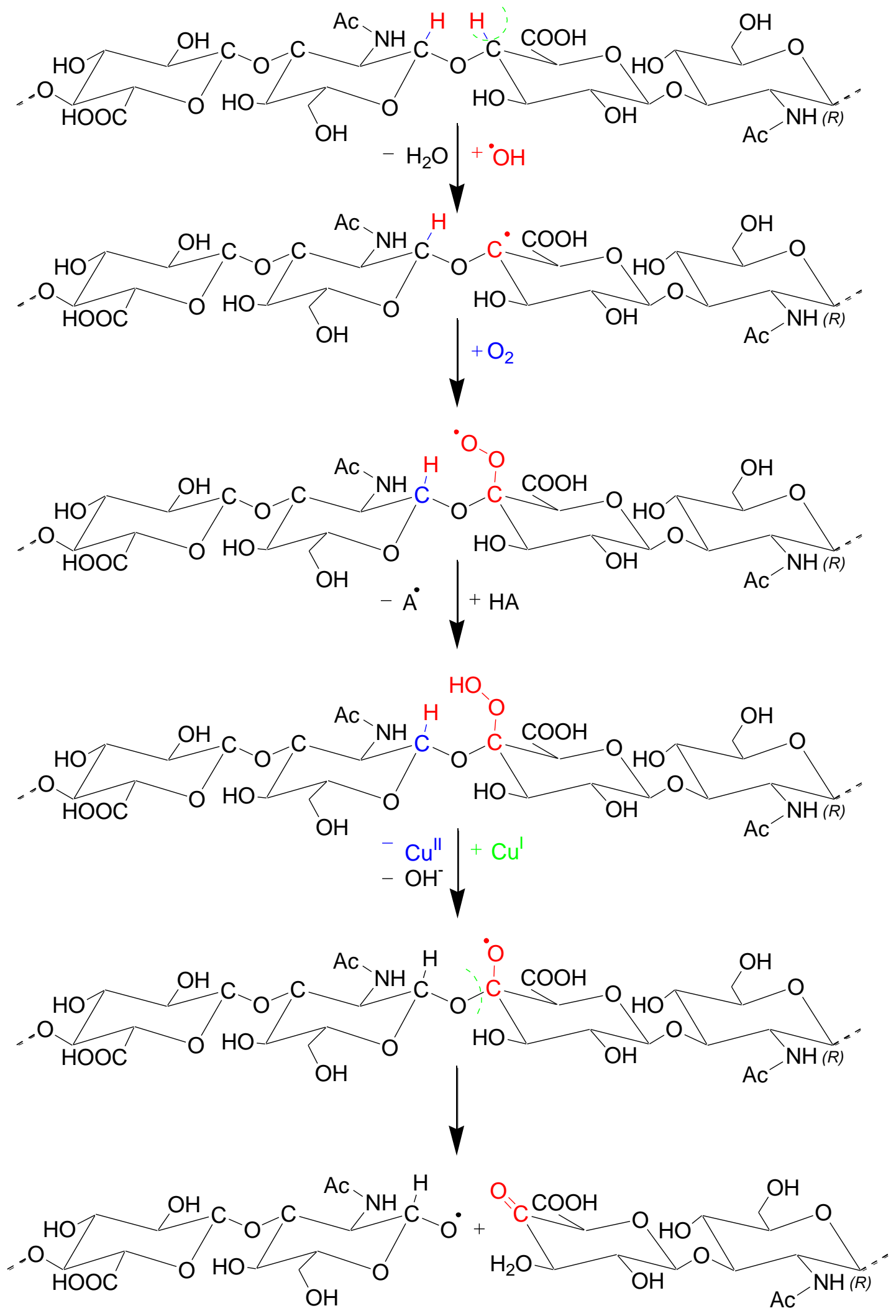

Fig. 4: Schematic degradation of HA under free radical stress (Hrabarova et al., 2012). 


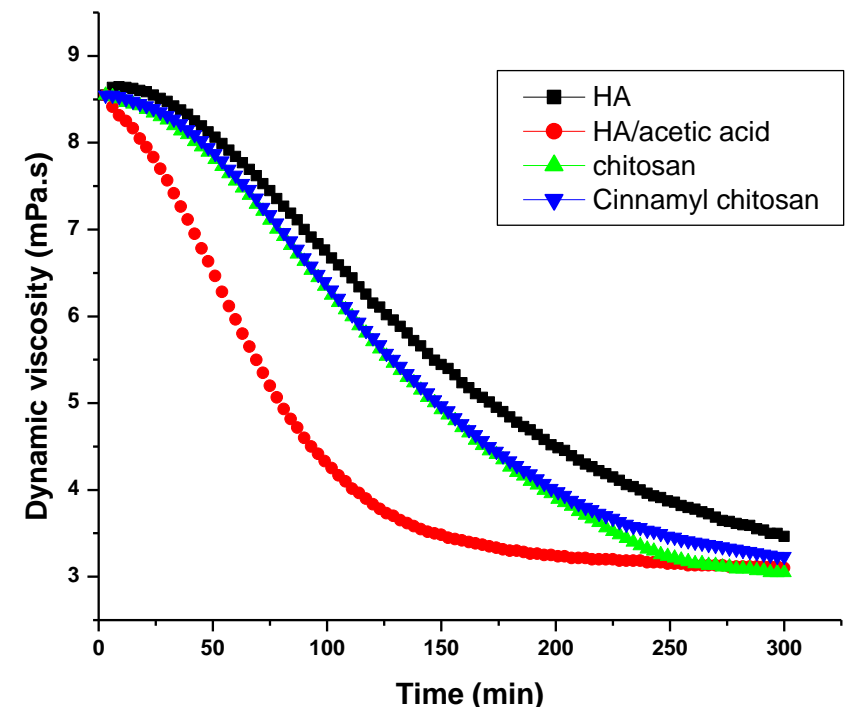

Fig. 5: Effect of chitosan and Cinnamyl chitosan dissolved in acetic acid $(0.5 \%)$ on the hyaluronan degradation induced by WBOS (black) when added to the reaction system before initiating the degradation of HA

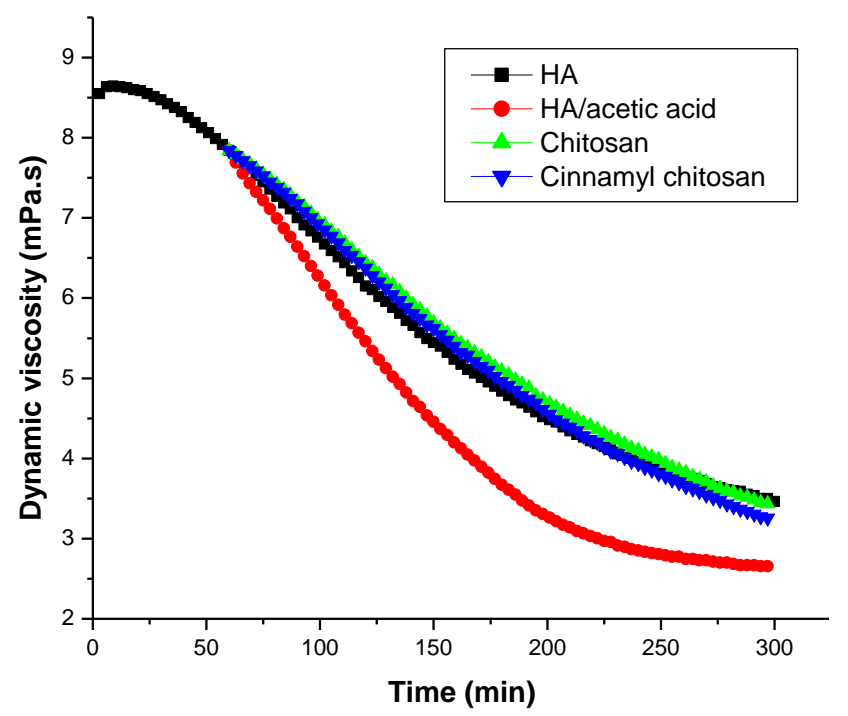

Fig. 6: Effect of chitosan and Cinnamyl chitosan dissolved in acetic acid $(0.5 \%)$ on the hyaluronan degradation induced by WBOS (black) when added to the reaction system after 1 hour of initiating the degradation of HA
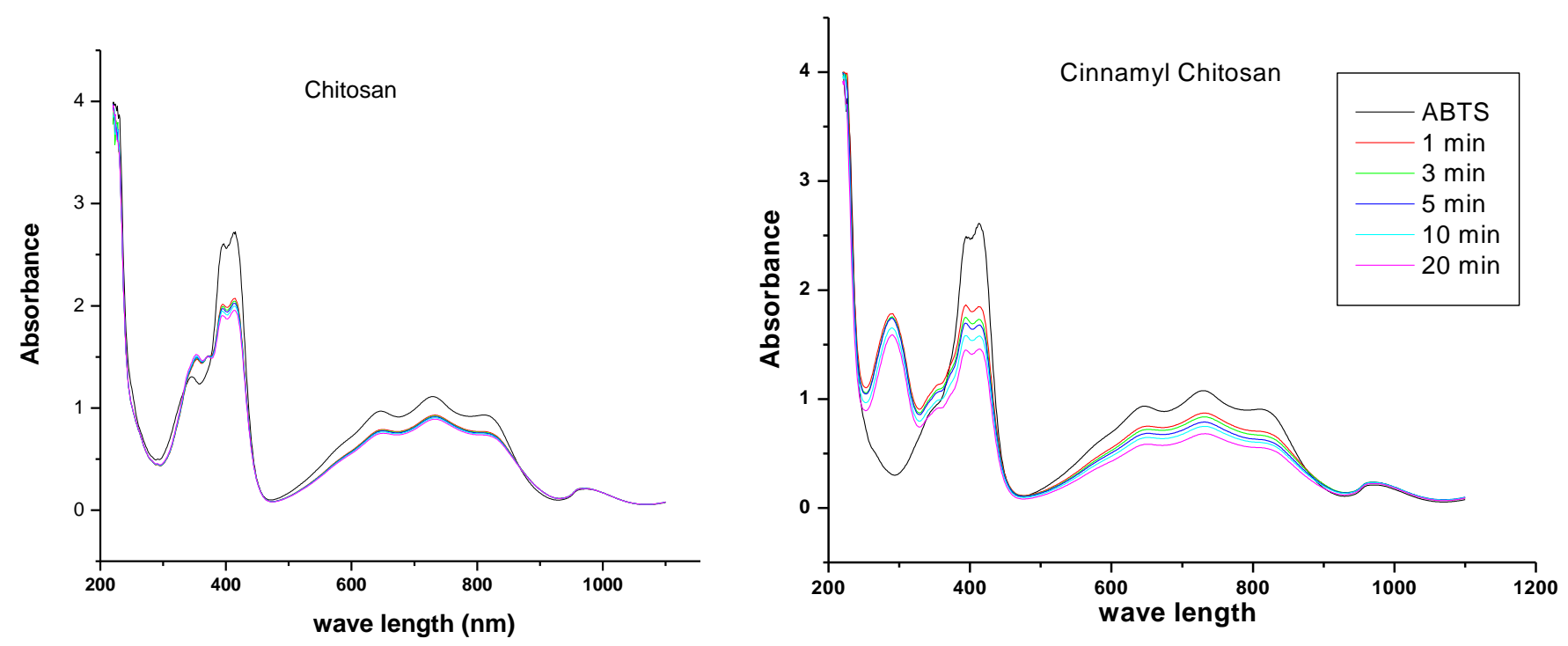

Fig. 7: Effect of Chitosan and cinnamyl chitosan (conc. $0.125 \mathrm{mg} / \mathrm{ml}$ ) on reducing $\mathrm{ABTS}^{\circ+}$ cation radical.

\section{ABTS Method}

Decolorization of $\mathrm{ABTS}^{++}$bluish green color was taken as monitor for measuring ability of antioxidant to donating electron. $\mathrm{ABTS}^{\circ}$ exhibits a bluish-green color with maximum absorbance values at 645,734 , and $815 \mathrm{~nm}$, this color rapidly decrease by acceptant electron from antioxidant substance ( $\operatorname{Re}$ et al., 1999; Hrabarova et al., 2010). Figure $(7,8)$ show effect of chitosan and cinnamyl chitosan on decolorization of
$\mathrm{ABTS}^{+}$cinnamyl chitosan show increase of decolorization effect than chitosan itself that may be result of attaching phenolic group on backbone. Phenolic groups have a reported potency as an electron donor than amine group of chitosan. Figure $(9,10)$ show the effect of dose concentration on decolorization of $\mathrm{ABTS}^{+}$. Again the figure show increases the ability of cinnamyl chitosan schiff base of chitosan itself on donating electron. 


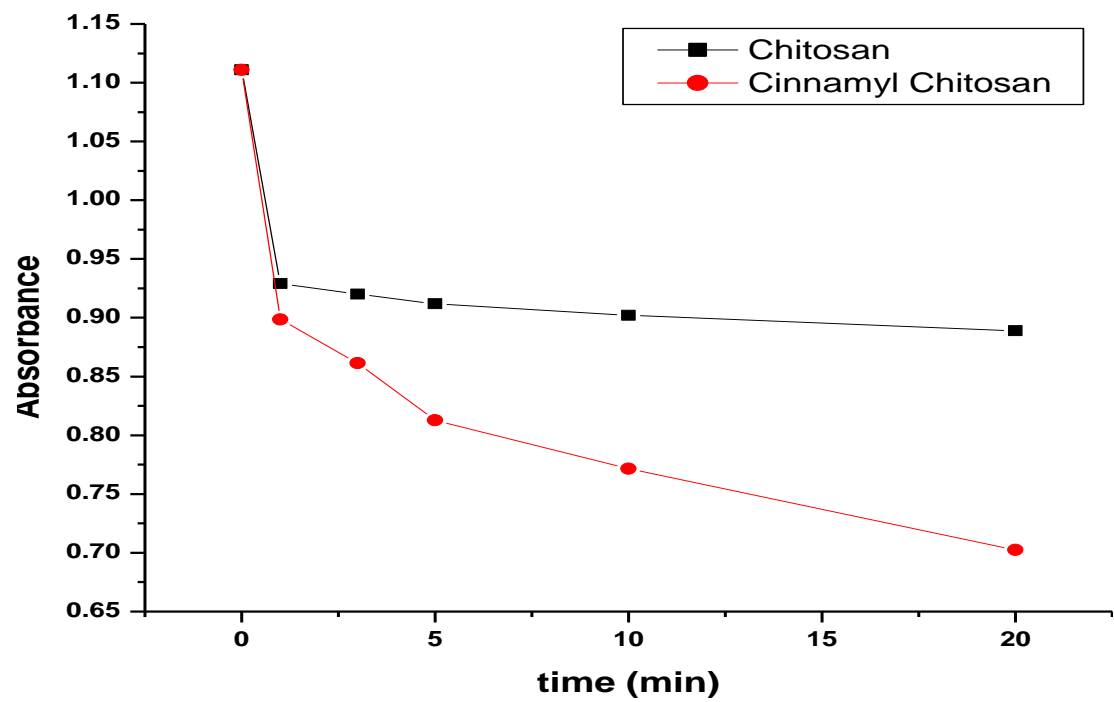

Fig. 8: Time dependence of absorbance at $730 \mathrm{~nm}$ measured after addition of polymer solution into the ABTS ${ }^{\bullet+}$
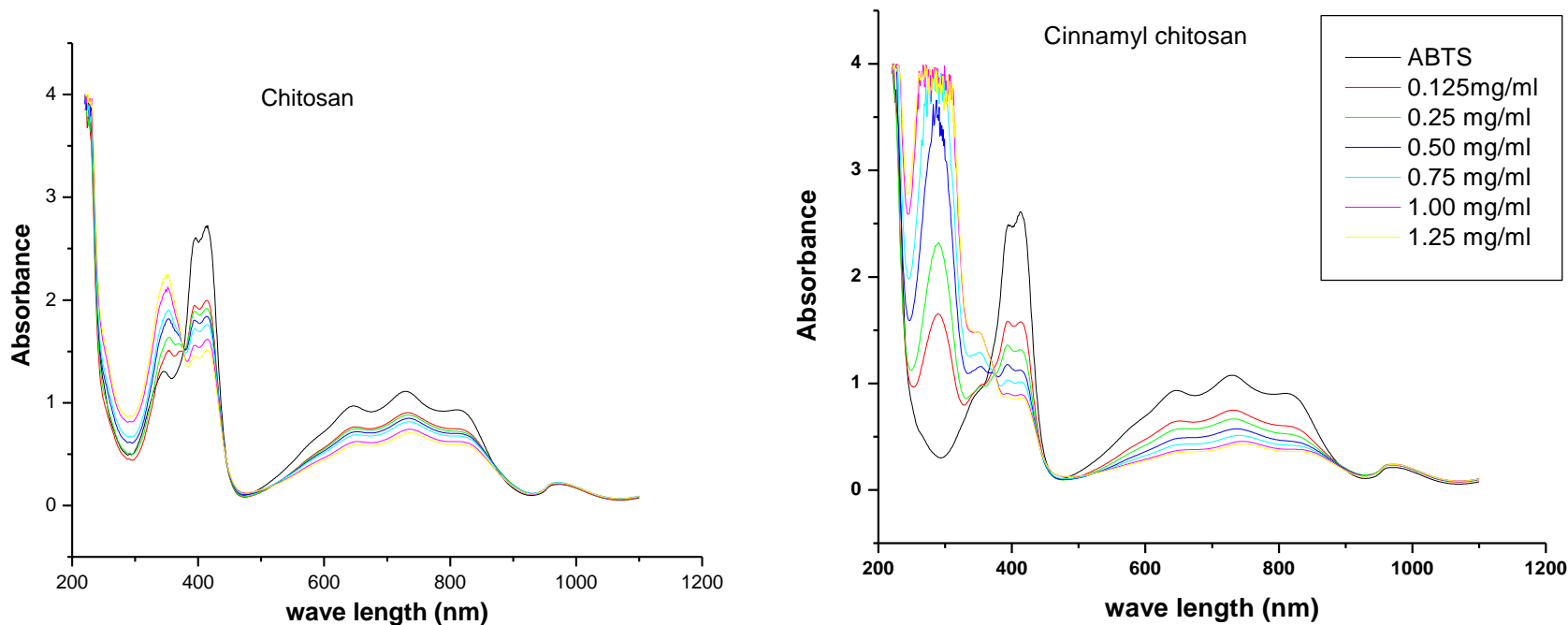

Fig. 9: Effect of Chitosan and cinnamyl chitosan concentration on reducing $\mathrm{ABTS}^{{ }^{+}}$cation radical measured 10 min after the reaction onset.

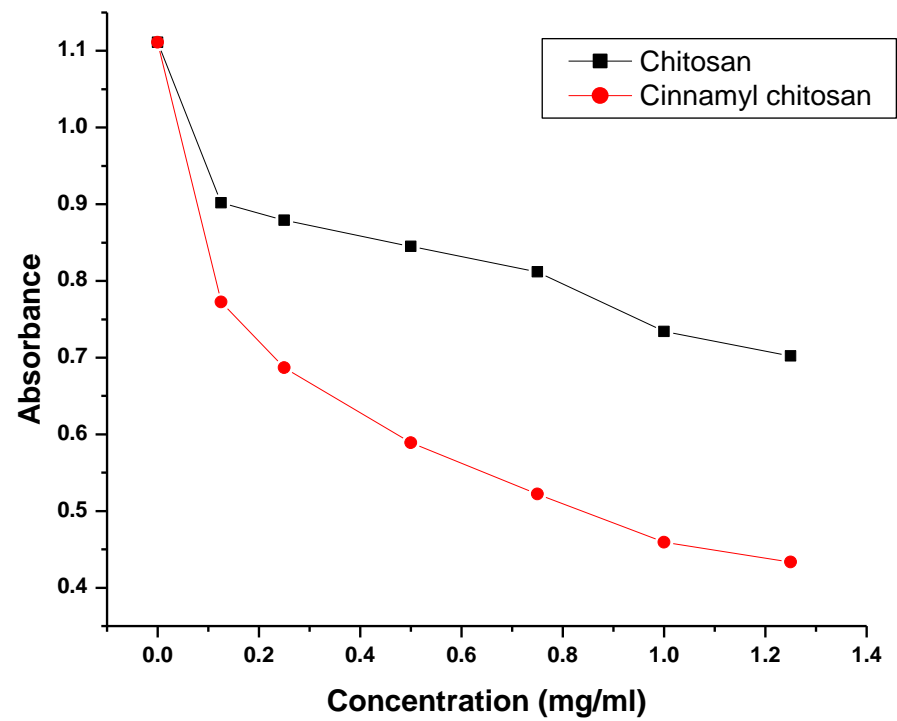

Fig. 10: dose dependency of $\mathrm{ABTS}^{*+}$ cation scavenging activity of Chitosan and cinnamyl chitosan measured 10 min after the reaction onset. 


\section{CONCLUSION}

Obtained results show no improves in chitosan hydroxyl free radical scavenger activity by modification. In the other hand it illustrates a clear increase in polymer electron donor tendency. This behavior may be attributed to immobilizing phenolic nucleus to chitosan backbone.

\section{REFERENCE}

Chen XG, Park HJ. Chemical characteristics of Ocarboxymethyl chitosans related to the preparation conditions," Carbohydrate Polymers, 2003; 53(4): 355-359.

Curti E, Britto D, Campana-Filho SP. Methylation of Chitosan with Iodomethane: Effect of Reaction Conditions on Chemoselectivity and Degree of Substitution. Macromolecular Bioscience, 2003; 3 (10):571576.

Dodane V, Vilivalam VD. Pharmaceutical applications of chitosan. Pharm. Sci. Technol. Today, 1998; 1: 246-253.

Fisher AEO, Naughton DP. Therapeutic chelators for the twenty first century: new treatments for iron and copper mediated inflammatory and neurological disorders. Curr. Drug Delivery, 2005; 2 (3): 261-268.

Hrabarova E, Valachova K, Juranek I, Soltes L. Free-Radical Degradation of High-Molar-Mass Hyaluronan Induced by Ascorbate plus Cupric Ions: Evaluation of Antioxidative Effect of Cysteine- Derived Compounds. CHEMISTRY \& BIODIVERSITY, 2012; 9: 309-317

Hrabarova E, Valachova K, Rapta P, Soltes L. An Alternative Standard for Trolox-Equivalent Antioxidant-Capacity Estimation Based on Thiol Antioxidants. Comparative 2,2'-Azinobis[3-ethylbenzothiazoline-6sulfonic Acid] Decolorization and Rotational Viscometry Study Regarding Hyaluronan Degradation. Chem Biodivers, 2010; 7(9):2191-2200.

Huang CC, Wang HF, Chen CH, Chen YJ, Yih KH. A study of four antioxidant activities and major chemical component analyses of twenty-five commonly used essential oils.J Cosmet Sci. 2011;62(4):393404.

Islama MM, Masumb SM, Rahmana MM, Mollab MAI, Shaikhc AA, Roya SK. Preparation of Chitosan from Shrimp Shell and Investigation of Its Properties. International Journal of Basic \& Applied Sciences IJBAS-IJENS, 2011; 11:1.

Jeon, YJ, Shahidi F, Kim SK. Preparation of chitin and chitosan oligomers and thir application in physiological functional foods. Food Rev. Int., 2000; 16: 159-176.

Kenawy E, Abdel-Hay F, Mohy Eldin MS, Tamer TM, Ibrahim EMA. Novel Aminated Chitosan-Aromatic Aldehydes Schiff Bases: Synthesis, Characterization and Bio-evaluation, Int. J. of Adv. Res, 2015; 3: $563-572$

Kumar MN, Muzzarelli RA, Muzzarelli C, Sashiwa H, Domb AJ. Chitosan Chemistry and Pharmaceutical Perspectives. Chem. Rev., 2004; 104: 6017-6084.

Mohy Eldin MS, Hashem AI, Omer AM, Tamer TM. Preparation, characterization and antimicrobial evaluation of novel cinnamyl chitosan Schiff base. Int. J. of Adv. Res. 2015b;3: 741-755.

Mohy Eldin MS, Hashem AI, Omer AM, Tamer TM. Wound dressing membranes based on chitosan: Preparation, characterization and biomedical evaluation. International Journal of Advanced Research, 2015; 3 (8): $908-922$
Mohy Eldin MS, Soliman EA, Hashem AI, Tamer TM. Chitosan Modified Membranes for Wound Dressing Applications: Preparations, Characterization and Bio-Evaluation. Trends Biomater. Artif. Organs, 2008; 22: 154-164.

Muchuweti M, Kativu E, Mupure CH, Chidewe C, Ndhlala AR, Benhura MAN. Phenolic Composition and Antioxidant Properties of Some Spices. American Journal of Food Technology, 2007; 2: 414-420.

Muzzarelli RAA, Muzzarelli CM, Terbojerich M. Chitin chemistry, upgrading a renewable source. Carbohydr European, 1997; 19:10-7.

Park PJ, Je JY, Kim SW. Free radical scavenging activities of different deacetylated chitosansusing ESR spectrometer.CarbohydrPolym, 2004; 55: 17-22.

Rapta P, Valachova K, Gemeiner P, Soltes L. High-Molar-Mass Hyaluronan Behavior During Testing Its Radical Scavenging Capacity in Organic and Aqueous Media: Effects of the Presence of Manganese(II) Ions. Chem. Biodiversity, 2009; 6: 162-169.

Re R, Pellegrini N, Proteggente A, Pannala A, Yang M, RiceEvans C. Antioxidant activity applying an improved ABTS radical cation decolorization assay.Free Radic Biol Med, 1999; 26(9-10):1231-7.

Rigby, G. Patent. Substantially Undegraded Deacetylated Chitin and Processes for Producing the Same. 1936, USA 2,040,879.

Shahidi F, Arachchi J KV, Jeon Y. Food application of chitin and chitosan. Trends Food Sci. Technol., 1999; 10: 37-51.

Shan B, Cai YZ, Sun M, Corke H. Antioxidant capacity of 26 spice extracts and characterization of their phenolic constituents.J Agric Food Chem, 2005 ; ; 53(20):7749-59

Soliman EA, El-Kousy SM, Abd-Elbary HM, Abou-zeid AR. "Low Molecular Weight Chitosan-based Schiff Bases: Synthesis, Characterization and Antibacterial Activity". American Journal of Food Technology, 2013; 8: 17-30.

Soltes L, Kogan G, Stankovska M, Mendichi R, Rychly J, Schiller J, Gemeiner P. Degradation of high-molar-mass hyaluronan and characterization of fragments Biomacromolecules, 2007; 8 (9): 2697-2705.

Soltes L, Stankovska M, Kogan G, Gemeiner P, Stern R. Contribution of oxidative-reductive reactions to high-molecular-weight hyaluronan catabolism. Chem. Biodiversity, 2005; 2: 1242 -1246.

Sousa F, Guebitz GM, Kokol V. Antimicrobial and antioxidant properties of chitosan enzymatically functionalized with flavonoids. Process Biochemistry, 2009; 44: 749-756

Vongchan P, Sajomsang W, Subyen D, Kongtawelerta P Anticoagulant activity of a sulfated chitosan. Carbohydrate Research, 2002; 337: 1239-1242.

Xie W, Xu P, Liu Q. Antioxidant activity of a water-soluble chitosan derivates. Bioorg Med Chem Lett, 2001; 11: 1699-701.

Xue C, Yu GT, Hirata J, Terao J, Lin H. Antioxidative activities of several marine polysacharides evaluated in a phosphatidylcholineliposomal suspension and organic solvents. Biosci Biotech Biochem, 1998; 62: 206-209.

\section{How to cite this article:}

Tamer TM, Valachová K, Mohy Eldin MS, Šoltés L. Free Radical Scavenger Activity of Cinnamyl Chitosan Schiff Base. J App Pharm Sci, 2016; 6 (01): 130-136. 